\title{
Glassifying Courses in the University Catalog
}

The authors contrast the university catalog and the card catalog and conclude that the university catalog is the best guide to the university's current scholarly interests. They urge that librarians study and classify courses therein, such as books, using the Library of Congress or Dewey Decimal schemes so that specific class numbers are grouped by academic department and become substantial spans. The profile can be used as a selection tool, as a correlating tool between curriculum, circulation and publishing, and as a device to aid weeding and shelving. General and specific guidelines for classifying, including a method for resolving apparent duplication of courses in different departments are presented. Time and unit figures are tabulated. Specific steps in classification and editing are described.

$\mathrm{T}$ HREE EARLIER PAPERS in this journal ${ }^{1}$ referred briefly to a device for tabulating data on books published, purchased, or circulated. This paper provides justification for the device, suggests several uses, and explains in detail how it is constructed.

\section{Justification}

Traditionally, librarians have regarded the card catalog and shelflist as the best guide to the scholarly interests of

1 William E. McGrath, "Determining and Allocating Book Funds for Current Domestic Buying," CRL, XXVIII (July 1967), 268-72; "Measuring Circulation According to Curriculum," CRL, XXIX (September 1968), 347-50; and Ralph C. Huntsinger and Gary R. Barber, "An Allocation Formula Derived from a Factor Analysis of Academic Departments," CRL, XXX (January 1969), 51-62.

Mr. McGrath is Director of Libraries, Miss Durand is Head Cataloger, University of Southwestern Louisiana, Lafayette, Louisiana. the university. The card catalog and the book collection were constructed with requests, for the most part, by faculty whose interests were usually specialized and whose tenure was not always permanent. Current book choices therefore did not always represent the fundamental current curriculum.

Even now it is the assigned task of the faculty library representative to request books which reflect the teaching mission of his department. His book choices are rarely questioned, nor need they be. What might be questioned is whether all the relevant books published in a given year are actually requested. Faculty turnover and specialized interests disrupt continuity and therefore may actually prevent the library's collection from fully reflecting departmental interest and need. Useful, then, would be a record which accurately reflects current departmental in- 
terests, has relative stability, and has a fairly high degree of continuity.

This paper proposes that the best such record is the university catalog, not the card catalog. The card catalog reflects the cumulative scholarly interests of the curriculum; the university catalog reflects the current, changing curriculum. Courses and whole programs are added or dropped. Whatever its shortcomings, however it changes, the university cata$\log$ is as thumbed and studied as the card catalog. Like books, courses are titled, listed and printed. What better record? Why not recognize the university catalog, then, and use it as a selection tool and guide to the collection? We could, if courses were classified by the Dewey Decimal or Library of Congress schemes, as are books in the card cata$\log$.

The DC and LC schemes are instruments too valuable to use on books alone. Other forms of information in libraries have been classified: abstracts by the Oxford decimal classification in Forestry Abstracts and Soils and Fertilizers, and abstracts on cards in many special libraries. Indeed, information scientists have put much thought into the problems of the structure and classification of knowledge in recent years. Why not college courses then? Courses are uniquely relevant and central to the library's purpose. A list of class numbers or groups of class numbers resulting from classification of the university catalog can be regarded as a department profile and can be used in many ways. For example, by correlating the class numbers to those in the American Book Publishing Record, or the British National Bibliography, clerks could use them to preselect books for critical review and final selection by a librarian. The list of class numbers could also be used as a tool to analyze the relationship of circulated books to courses.

Study of the university catalog is one excellent way to learn about the cur- riculum and is an unusual exercise for catalogers. University of Southwestern Louisiana catalogers stated, after classifying 1,346 courses, that they had gained therefrom a far better understanding of the university program. It gave them a perspective they did not have before. Using both the DC and LC schemes for an unconventional application provided insights not possible otherwise.

In addition to the applications suggested above, several more are listed below. Undoubtedly there are others. In each of the following, class numbers can be grouped under each department in the catalog, creating a tabulating framework for correlation analysis, and other statistical studies.

1. Assessing the collection. Class numbers for existing as well as new courses and departments can be compared to the shelflist or other classified bibliographies to ascertain adequacy or lack of material.

2. As a buying guide. Currently published books with class numbers falling into the same groups as those in the university catalog should be first choices for purchase.

3. MARC tapes as a selection tool. Class numbers on the MARC tapes could be searched and compared to the list of class numbers in the university catalog. Titles of LC books with call numbers that match the class numbers would have purchasing priority. Important material outside the class number profile would be reviewed and selected by traditional methods.

4. As a guide to the collection. Teachers may use groups of numbers assigned to each course as a guide to relevant material in the stacks.

5. Circulation. The number of books circulated in each departmental category could be profitably correlated with the number of books in the existing collection. 
6. In-library use. The books used in the library could be correlated with those taken out of the library.

7. Weeding device. Books with class numbers not in the listed groups can be regarded as having low relevance and if they have no other value may be considered for discard.

8. As a shelving and storage aid. Books in the highly relevant categories can be shelved in optimum locations. Those not in relevant categories can be stored in less accessible places.

So much for the argument. The following discussion is intended for those who may be interested in applying the device to their own situation.

\section{The Classification Process}

The first step in the classification process is to assign numbers to individual courses in the same manner that numbers are assigned to books. There is no need, however, to restrict classification to one number. If more than one number applies, each may be listed. At the University of Southwestern Louisiana nearly two numbers per course were assigned and entered in the margin next to the descriptions in the catalog. A 3"x 5" card was then prepared for each number assigned, including, in addition to the number, the department and course number. Editing then reduced the number of class numbers considerably, as can be seen in Table 1. Each cataloger reviewed specific numbers assigned to each department, and found that (1) many class numbers were repeated from course to course and (2) a long list of specific class numbers had accumulated with very few gaps between. The editing process simply consisted of (1) dropping all but one each of the many repeated numbers while listing on one $3^{\prime \prime} \times 5$ " card all the courses having that one number, and (2) listing on another 3 "x 5 " card the first and last of the long list of class numbers, it being agreed that all of the numbers in between were included. Long, inclusive spans were thus created. For example: QA 303-320 was given to calculus courses; QA $331-355$, to complex variables; QA 331-360, to complex analysis; QA 371-381, to differential equations. Since these courses are all in the mathematics department, the four

TABLE 1

Number of Departments, Courses, and Class Numbers and Time Needed to Complete Project

\begin{tabular}{|c|c|}
\hline 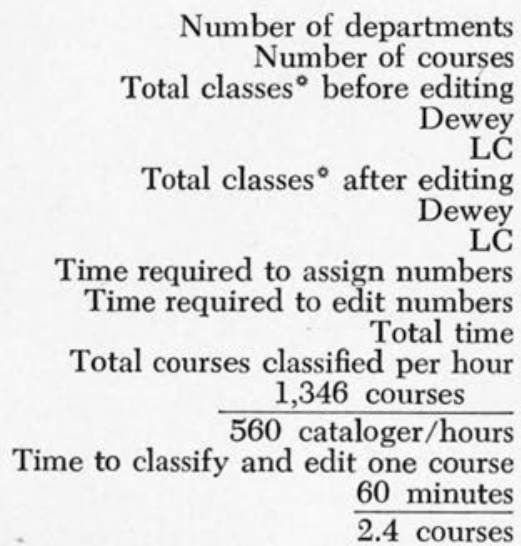 & $\begin{array}{l}64 \\
1,346 \\
2,579 \\
2,383 \\
315 \\
463 \\
320 \text { cataloger/hours } \\
240 \text { cataloger/hours } \\
560 \text { cataloger/hours } \\
2.4 \text { courses per hr. } \\
25 \text { minutes (average) }\end{array}$ \\
\hline
\end{tabular}

\footnotetext{
- Individual numbers and spans of numbers
} 
short spans were made one long span, QA 303-381, and labeled Mathematics. The apparently nonexistent numbers, QA 321-330 and QA 361-370 are assumed to exist for the sake of closing the span. The edited class numbers were then arranged sequentially. An example follows:

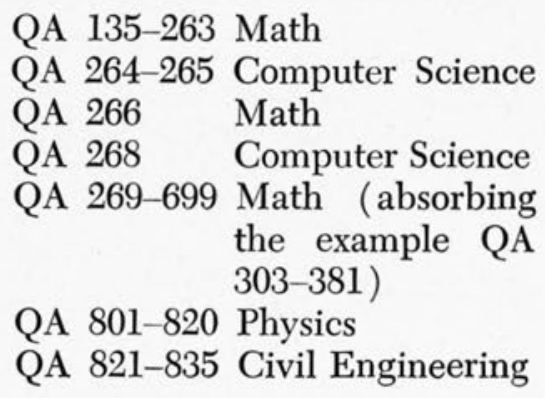

The numbers were then grouped according to department:

Computer Science:
Q 300-380
QA 74-76.8
QA 264-265
QA 268
Z 699-699.5

Math:

HF 5691-5716

QA 11

QA 39

QA 135-263

QA 266

QA 269-699

QC 851-999

TA $329-347$

Physics:

QA $801-820$

Civil Engineering:

QA 821-835

\section{Specific Guidelines}

To coordinate the work of University of Southwestern Louisiana catalogers and to establish uniformity, the authors developed the following guidelines and instructions.
1. Single listings. A number assigned to more than one course within the same department need only be listed once. It is useful, however, to list these courses on one card for cross-referencing.

2. Spans. Specific numbers should be grouped together, whenever possible, to form spans. Thus, if 574 and 574.1 are separately assigned, then they can be grouped together to form the span, 574-574.1. Additional numbers can be added to make the span even greater. In constructing a span, build up from the specific to the general.

3. Specific numbers. Use specific numbers whenever possible to assure that each department has its own group of numbers, while at the same time keeping the number of spans to a minimum by making them as long and as inclusive as possible. The more specific, the more accurate; but the more inclusive, the less cumbersome. (See also Guideline no. 6.)

4. Class numbers not in schedules. Spans may include numbers not specifically listed in the LC or DC schedules. For example, the span 184-186 may be assumed to include 185.5 , even though no such number is specifically scheduled.

5. Ending a number. A number in a span will end with the last number for that subject listed in the LC or DC schedule. For example, biogeography ends with 574.99 rather than 574.9 , because 574.9 does not include all the subjects between 574.9 and 574.99. It is not necessary to stretch the number out further, e.g., 574.99999 . . . because no such number is listed in Dewey. The last num-

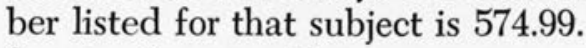

6. Survey Courses. If a survey course is offered in a department which offers specific courses in the same subject, do not assign any number. If no specific courses are offered within the 
general subject of the survey course, then assign as specific a number as possible. For example, instead of QA 1-935 for a survey course in mathematics, use

\section{QA 36 (Encyclopedic Works, Textbooks, Compends, etc.)}

And instead of QE 1-996 for a course in Orientation Geology, use

$$
\text { QE 26-31, QE 41, and QE } 61
$$

7. Objectivity. When you discover a class number for a subject which you think ought to be included in a course description, but the description does not actually include the subject, do not assign that number.

8. Duplication. (When a course in Department $\mathrm{B}$ is assigned a number already assigned to Department A.) All decisions, even when the factors seem complex, can be reduced to an either/or situation. The technique is to determine what are the vital factors, to organize them in an either/or manner, then test them with the individual case. To help resolve the problem of duplication, Figure 1 shows a flow chart based on the either/or logic.

To enable librarians to make an estimate of the time needed to classify the college catalog, University of Southwestern Louisiana catalogers kept track of the time spent on their study. The figures are given in Table 1.

\section{Conclusions}

University of Southwestern Louisiana catalogers, after the project, offered several observations worth repeating. Many of the problems were the usual ones associated with classification and were already familiar, but a number of the observations required careful study. The most difficult was Duplication of
Courses (Guideline no. 8). If one department offered a course which was identical or nearly identical to a course offered by another department, which one should be assigned the relevant class number or group of class numbers? The Guideline could not resolve every conflict. Several duplications were unresolvable and were set aside for consultation with departments or even the curriculum committee.

The catalogers felt that, ideally, one cataloger should classify the entire catalog. But the work load was too heavy for one cataloger and so was divided among four, each cataloger being assigned specific departments. To help reconcile the inevitably divergent interpretations of courses and guidelines, one person, the head cataloger, performed one final overall editing.

Several professors, especially in the science departments, devoted many hours interpreting course content and suggesting class numbers. On the whole, they were quite interested in the project and thought it worthwhile.

The catalogers ran into another problem-an old one-the poor course descriptions. Quality of these descriptions varies greatly. Some are too wordy or obscure, others are too general or cryptic. We decided that course descriptions would be interpreted quite literally. No numbers were assigned to a subject not explicit in that course description. This, of course, meant that many large blocks of class numbers would not appear in our final list, an inherent feature of the entire project.

The catalogers admitted that Guideline no. 7 was also difficult to follow. To list class numbers for subjects we think are important was and is a great temptation. Important though they may be, the university catalog was the authority. We could not, on our own authority, list these important subjects unless they were in the catalog. 


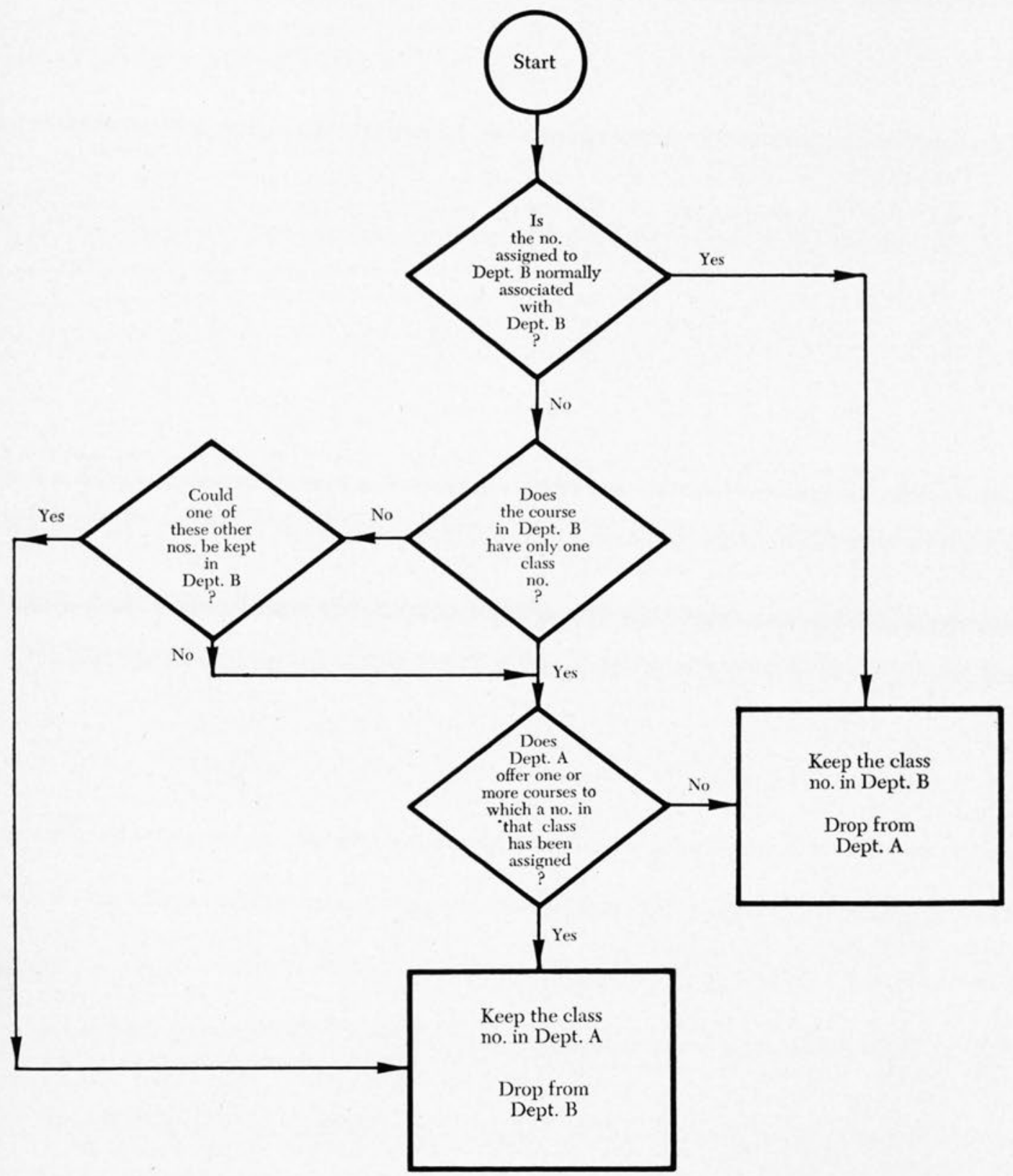

Figure 1. Decision flow chart. What to do when a classification number assigned to a course in Department B has already been assigned to a course in Department A. The number fits both courses equally well. 
This raises the question of whether excluded numbers are irrelevant numbers. Since we are aware of the considerable subjectivity involved, we prefer to say that most books with class numbers among the listed numbers have a high relevance, and that books with class numbers not among the listed numbers have a lower relevance. We expect that, occasionally, some books outside the profile will be highly relevant and that some books within the profile will be highly irrelevant. This system makes no judgments about the merits or quality of each book. It simply says that based on a subject analysis of the course content, and the resulting class number profile, every book, whether a very good one or a very bad one, has either a high or a low relevance to the curriculum. Naturally, to assure year-to-year relevance the list would need annual up- dating with numbers for new courses added and those for dropped courses deleted.

Ideally, we might rate the relevance of books on an arbitrary scale ranging from 0.0 to 1.0. Books with class numbers matching those in our list would be perfectly relevant and would have a rank of 1.0. A book with a class number not in our list-for example, QA 267might be assigned a relevance of .5 because, after all, QA 267 is mathematics and we do have a mathematics department. A book with a class number for a subject not assignable to any department might have a relevance of 0.0 . Finally, it may sometimes be practical to rank only the class numbers. Such a scale of relevance, for books or class numbers, could be the next development in a system of classified courses.

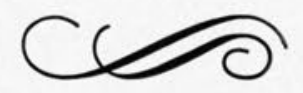

